biological conditioning of the environment, play a part in the phenomenon of succession in the sea and elsewhere. If this is correct, then it seems likely that Prof. Salisbury's suggestion regarding biological competition may fairly be seen within the wider field of general ecological succession. In particular relation to penicillin, it would be of interest to know whether its effects on the ecological successors of Penicillium notatum are harmful or beneficial, since it is possible that at least one of these has acquired tolerance of the excretion, or even 'made use' of it in an adaptive manner.

As a further example of the possible importance of such processes, I should like to refer again ${ }^{6}$ to the part which biological conditioning of both types may have played in that major 'succession', evolution itself. It has been pointed out by P. G. 'Espinasse' that physiologically active substances are frequently metabolites in which the present-day effects have followed upon their first production. Much of the history of evolution has concerned the development by living things of responses to metabolites, sometimes their own and sometimes produced by others. Those organisms which developed 'satisfactory' responses succeeded, and those which did not, failed. Particularly in so far as evolution may first have proceeded in an aquatic environment, the gradual production of different external metabolites must at each stage have determined to some extent which of new genetic forms should 'succeed' in the field.

Since this letter was written, H. McIlwain's important article has been published ${ }^{8}$, and attention should be directed here to his most relevant remarks on biological interactions.

Department of Oceanography, University College, Hull.

1 Salisbury, E. J., NATuRE, 153, 170 (1944)

2 Pickering, S., Ann. Bot., 31, 183 (1917).

${ }^{3}$ Hardy, A. C., Discovery Reports, 11, 273 (1935).

"Allee, W. C., "Animal Aggregations" (Univ. Chicago Press, 1931). -Allee, W. C., Biol. Rev. Camb. Phil. Soc., 9, 1 (1934).

'Lucas, C. E., J. Cons. Int. l'Explor. Mer., 13, 309 (1938).

7 'Espinasse, P. G., Proc. Zool. Soc., Lond., A, 109, 247 (1940).

s Mcllwain. H., Natore, 153, 300 (1944).

\section{p-Aminobenzoic Acid and its Effect on the Sulphanilamide Inhibition of the Growth of Oat Roots}

THere have been many ohservations on the inhibitory effect of sulphanilamide on the growth of various organisms such as bacteria, yeast, fungi and higher plants. In a recent letter by Brian ${ }^{1}$, it was shown that sulphanilamide caused an inhibition of the coleoptile growth of wheat seedlings. The general observation was also made that root-growth was stunted. Brian's results seemed to indicate that the antisulphanilamide activity of $p$-aminobenzoic acid could be absolute, indicating that $p$-aminobenzoic arid was an essential metabolite for wheat seedlings.

In view of these findings, it might be of interest to others in this field to record some observations made in these laboratories on the growth of oats, during the course of some work on $H 11$ extract. It was desirable at one stage to maintain a stock solution free from bacterial growth, and attention natur-
Table 1. Growth of roots in test solutions as a percentage OF THE GROWTH IN WATER.

\begin{tabular}{lcccccr}
\multicolumn{1}{c}{ Test substance } & & $0 \cdot 00005$ & $0 \cdot 0001$ & $0 \cdot 00025$ & $0 \cdot 0005$ & $0 \cdot 001$ \\
Sulphanilamide & $\ldots$ & $101 \cdot 1$ & $97 \cdot 4$ & $85 \cdot 8$ & $74 \cdot 8$ & $45 \cdot 1$ \\
$p$-Aminobenzoic acid &.. & 96.8 & $96 \cdot 0$ & $97 \cdot 3$ & $93 \cdot 2$ & $91 \cdot 0$
\end{tabular}

Le 2. Growth of roots in test solutions as a Percentage of the growth in water. Concentration of $p$-aminobenzoic acid $\begin{array}{cccccc}42 \cdot 1 & 0.00005 M & 0.0001 M & 0.00025 M & 0.0005 M & 0.001 M \\ 50.0 & 50.5 & 57.0 & 55.3 & 53.0\end{array}$ $42 \cdot 1 \quad 50 \cdot 0$ $50 \cdot 5$

ally turned to sulphanilamide and to the range of concentrations which would be non-toxic to the plants. The seeds (var. Victory, $O N$ 160) were germinated and grown for 48 hours in the dark at $25^{\circ} \mathrm{C}$. using the technique previously described ${ }^{2}$.

From Table $l$ it is seen that the inhibition of growth by sulphanilamide alone first began to be observable at a concentration of approximately $0.0002 M$, while in a concentration of $0.001 M$ the growth of the roots was approximately 45 per cent of that in tap water. With $p$-aminobenzoic acid alone, the roots showed no stimulatory effects, and indeed some slight degree of inhibition appeared at $0.001 M$. Using $p$-aminobenzoic acid in relatively non-toxic concentrations, it was not possible to neutralize completely the inhibitory effect of sulphanilamide (Table 2). Some degree of anti-sulphanilamide effect could be obtained, the growth-value increasing from about 45 per cent to a maximum of 57 per cent, a difference representing that between the inhibition caused by a $0.001 M$ and a $0.0008 M$ solution of sulphanilamide. That is to say, a concentration equivalent to about $0.0002 M$ sulphanilamide had been 'neutralized' in its effect by $p$-amino-benzoic acid. With a weaker concentration of sulphanilamide $(0.0005 M$ or less $)$ there can be an absolute anti-sulphanilamide effect by the $p$-amino-benzoic acid.

There is thus a 'residual' inhibitory effect not affected by the concomitant application of $p$-aminobenzoic acid when the sulphanilamide is present as a $0.001 M$ solution. These results have been confirmed several times, and we must conclude that the 'residual' inhibition noted above represents an effect of sulphanilamide other than the usually accepted one. Sulphanilamide may indeed be able to 'lock' more than one system of reactions, as, for example, the anti-catalase effect noted by Shinn, Main and Mellon ${ }^{3}$, and the inhibition of the oxidation of $p$-aminobenzoic acid catalysed by peroxidase 4 .

From the present findings it would appear that $p$-aminobenzoic acid is not, in the fullest sense of the term, an 'essential' metabolite for the growth of oat roots (var. Victory) when these are grown for 48 hours in the dark at $25^{\circ} \mathrm{C}$. It does, however, play some part in the physiology of the seedling growth and is, no doubt, present in the seed. It may well be that some other analogue of sulphanilamide could be shown to be such an 'essential' metabolite, a point of interest to workers on the growth of isolated roots of monoeotyledons.

I wish to express my thanks to Mr. L. G. Wilkinson for his assistance in this work.

Department of Plant Physiology,

\section{R. Forbes Jones.}

Hosa Research Laboratories,

Sunbury-on-Thames, Middlesex.

Feb. 23.

${ }^{1}$ Brian, P. W., NATURe, 153, 83 (1944).

${ }^{2}$ Forbes Jones, R., and Baker, H. G. Ann. Bot., N.S., 7, 379 (1943).

${ }^{3}$ Shinn, R. W., Main, H. J., and Mellon, R. R., Proc Soc, Exp. Biol and Med., 44, 591 (1938).

4 Lipmann, F., J. Biol. Chem., 139, 977 (1941). 